\title{
AS INFLUÊNCIAS DOS MEGAEVENTOS ESPORTIVOS NA AGENDA E POLÍTICAS ESPORTIVAS: PLANEJAMENTO, ARRANJO INSTITU- CIONAL, ORDENAMENTO JURÍDICO E FINANCIAMENTO
}

\author{
Wagner Barbosa Matias \\ Universidade de Brasília, Brasília, Distrito Federal, Brasil \\ Fernando Mascarenhas \\ Universidade de Brasília, Brasília, Distrito Federal, Brasil
}

\begin{abstract}
Resumo
Este texto trata dos megaeventos esportivos, especificamente sobre as influências exercitadas referente à agenda e às políticas esportivas. Para tanto, realizou se uma revisão de literatura sobre megaeventos esportivos e política de esporte, bem como uma pesquisa documental, de abordagem qualitativa e de cunho exploratória. Percebeu-se que os megaeventos esportivos estão mais associados a questões mercantis de (re)estruturação de novos mercados, cidades e nichos econômicos do que questões de democratização do esporte. O que provocou mudanças no planejamento, no arranjo institucional e jurídico e no financiamento do esporte no Brasil.
\end{abstract}

Palavras-chave: Estado. Políticas esportivas. Megaeventos esportivos.

\section{Introdução}

As políticas públicas de esporte no Brasil, desde a realização dos Jogos Pan Americano de 2007 e a consequente "conquista" no mesmo ano do direito de sediar a Copa FIFA 2014, e a escolha da cidade do Rio de Janeiro, em outubro de 2009, como anfitriã dos Jogos Olímpicos de 2016, conjugado à realização em solo nacional de eventos, como os Jogos Mundiais Militares 2011, a Copa das Confederações de Futebol 2013 e diversos mundiais das modalidades olímpicas que, no bojo, acabam desembarcando no país, têm nos eventos e megaeventos esportivos o princípio organizador e a pauta prioritária da agenda governamental (MASCARENHAS et al., 2012).

Isso ocorre em meio à sizígia esportiva, ou seja, o alinhamento da sociedade política (com interesse de incrementar o comércio local e de projetar o país no exterior), dos dirigentes esportivos (que se consolidam enquanto atores sociais e lucram com a venda dos eventos), e as megacorporações - que valorizam seu capital e ganham recursos públicos com as grandes obras e os serviços esportivos.

Assim, a entrada dos megaeventos na agenda pública produziu uma série de modificações, no que se refere: a) a forma e os objetivos do planejamento governamental para o setor; b) a estrutura institucional e da sociedade civil; c) a legislação construída para a realização dos megaeventos; e d) o financiamento do campo esportivo. 
Este estudo se dedica a refletir sobre as influências dos megaeventos esportivos na agenda e nas políticas de esporte, em especial, no âmbito do Governo Federal. Nesse sentido, os aspectos levantados anteriormente serão explorados de maneira crítica, buscando os interesses presente nas ações e nos ordenamentos legais apresentados.

\section{Delineamento}

Os estudos sobre megaeventos esportivos no Brasil ainda são poucos e recentes. No mapeamento realizado por Miranda e Mascarenhas (2011) foram encontrados até 2010, apenas 24 artigos publicados nos principais periódicos da Educação Física e Ciências do Esporte (Revista Motriz, Revista Movimento, Revista da Educação Física, Revista Brasileira da Educação Físicae Esporte, Pensar a Prática eMotrivivência). Nos últimos anos, a RevistaMotrivivência publicou um número sobre o tema ( $\mathrm{n}^{\circ}$ 40/2013) e outros textos circularam nos periódicos citados, como: Damo (2012), Mascarenhas (2012) e Castellani Filho (2014).

Nesse sentido, buscamos contribuir com o debate sobre a temática. Para construção do texto, realizou se uma revisão de literatura sobre megaeventos esportivos e política de esporte, bem como uma pesquisa documental, de abordagem qualitativa e de cunho exploratória.

Os dados foram coletados nos documentos oficiais publicados pelo Governo Federal e entidades esportivas, bem como nos documentos produzidos pelos movimentos sociais relacionados aos megaeventos esportivos.

\section{Os megaeventos esportivos}

De acordo com Castellani Filho (2014, p. 105), os megaeventos esportivos no Brasil são "menos resultado da articulação do campo esportivo brasileiro e manifestação de sua força e mais a conjugação de interesses de Governo centrados em uma determinada compreensão de desenvolvimento e de inserção protagônica do país no cenário mundial".

Destaca-se que a atração de espetáculos, especialmente os internacionais de grande visibilidade garante ao país sede e à cidade anfitriã exposição na mídia e o deslocamento para seu território de capitais públicos e privados, nacionais e internacionais, impulsionando as adequações urbanas, sociais, econômicas e políticas demandadas pelo setor privado.

A quantidade de eventos e megaeventos que uma cidade pode receber em um ano, é grande, quanto melhor a infraestrutura para recepcionar os espetáculos, mais se destacará no mercado mundial. No universo dos eventos caracterizados como internacionais, a International Congress \& Convention Association (ICCA) anualmente divulga ranking dos países e cidades de acordo com a quantidade de eventos sediados. Assim, com o resultado, os gestores podem avaliar o status de sua cidade no cenário de concorrência internacional (RAEDER, 2010).

Porém, o número de eventos que podem provocar mudanças significativas no tecido social/urbano das cidades é reduzido. Por isso, a predileção da governança urbana pelos megaeventos, especialmente os produtos Copa do Mundo FIFA e os Jogos Olímpicos (CASTRO, 2012).

Estas commodities culturais chegam de forma in natura aos países que possuem a franquia e possibilitam aos seus proprietários, bem como, aos parceiros (emissoras de televisão e patrocinadores) renda monopolista. Além destes, também são beneficiados os agentes diretamente envolvidos na construção dos equipamentos esportivos e da infraestrutura programada, os setores ligados ao turismo, aos serviços e produtos de consumo e tecnologia, os especuladores imobiliários etc. 
A população de baixa renda sofre com as remoções e expulsões, com a exploração da sua força de trabalho, quando não são proibidas de exercê-la e com o monitoramento armado e social - políticas de manejo social do risco - do Estado.

Os prognósticos ex ante, na maioria das vezes superestimados, servem apenas para legitimar o derramamento de recursos públicos. Isto ocorre em todos os países sedes, inclusive no Brasil que irá receber tanto a Copa FIFA, quanto os Jogos Olímpicos.

Neste sentido, além dos impactos negativos para população de baixa renda, os legados tão anunciados antes e na preparação dos megaeventos, servem para legitimar os elevados gastos públicos, na maioria das vezes com superfaturamento, como ocorreu no Pan de 2007 (CASTRO, 2012).

A seguir apresenta-se as transformações no processo de formulação e planejamento das políticas esportivas, especificamente o novo direcionamento da Conferência Nacional de Esporte e do Plano Plurianual (PPA).

\section{A formulação das políticas esportivas no contexto dos megaeventos esportivos}

Uma das primeiras medidas governamentais, após a definição do país como sede da Copa FIFA 2014 e, principalmente, dos Jogos Olímpicos e Paraolímpicos de 2016, foi convocar a III Conferência Nacional do Esporte, com o propósito de elaborar um Plano Decenal do Esporte e Lazer (PDEL).

Diferentemente das duas anteriores (BRASIL, 2004a; 2006a) em que as discussões ocorreram com o foco no esporte como direito e na constituição de um Sistema Nacional do Esporte e Lazer (SNEL), nessa terceira edição, o evento já expressa o consenso obtido pelo bloco de poder, tendo os megaeventos como princípio organizador de toda a agenda. No período de preparação da III Conferência, o então Ministro do Esporte, Orlando Silva disse o seguinte:

A vitória do Rio de Janeiro como cidade sede para as Olimpíadas e Para-olimpíadas de 2016, concretiza os esforços do governo federal para colocar o país no centro dos grandes eventos esportivos mundiais. Um marco decisivo foi a realização, em 2007, no Rio, dos melhores Jogos Pan-Americanos da história. Trouxemos a Copa de 2014 e agora as Olimpíadas 2016, um feito inédito. A conquista de sediar os maiores eventos esportivos do mundo se sustenta no paradigma dos legados que contribui com o crescimento do Brasil, a transformação urbana das cidades e o desenvolvimento social sustentável por meio do esporte. (...) Esse conjunto de fatores torna a política do esporte estratégica para o desenvolvimento do país que pretende ser a quinta potência econômica em 2016 e, figurar entre as dez maiores potências olímpicas do mundo (BRASIL, 2009a, p.7).

É neste cenário de exaltação das "conquistas" e do esporte como fator de fomentador do crescimento econômico, visto não como direito, que foi realizada esta terceira edição do evento. De acordo com Matias (2013), a III Conferência Nacional do Esporte não tinha como meta o debate sobre o SNEL ou mesmo consolidar um Plano estratégico para o setor. Na verdade, o desejo era justificar e legitimar a realização dos Jogos Olímpicos no país, fato que emergiu por fora das discussões da I e II Conferência e mesmo das reuniões do Conselho Nacional do Esporte.

A determinação de trazer eventos de tamanha proporção e de visibilidade internacional para o Brasil não tem base nas deliberações nas duas primeiras Conferências Nacionais e nem 
na Política Nacional do Esporte (BRASIL, 2005), os três documentos que deveriam balizar o Plano Plurianual (PPA) de 2008 a 2011, e consequentemente às ações do Executivo para o esporte e lazer (BRASIL, 2004a; 2005; 2006a). Também no próprio PPA do período em que o governo assumiu o compromisso internacional de sediar os eventos (PPA 2004/2007) não há nenhuma menção sobre receber eventos esportivos de tamanha importância (CASTELAN, 2011).

O resultado da III Conferência sintetizada por Melo (2011, p. 306) é apresentado da seguinte forma:

Ao desenvolver cada um dos dez eixos da III Conferência Nacional ${ }^{1}$ fica explícito como o indicativo do bloco no poder deve ser traduzido tanto por aprofundar o tipo de desenvolvimento esportivo amplamente relacionado com as demandas do conjunto da classe burguesa nacional e internacional, como sedimentar os mecanismos de obtenção do consenso em torno dessas opções. Concretamente, tais mecanismos querem dizer a prorrogação da lei de Incentivo fiscal do esporte até 2025; o incentivo da chamada ginástica laboral, por meio da "... articulação de foros locais, envolvendo os setores públicos, privados, terceiro setor e corporativos para a implementação e gestão compartilhada de ações que favoreçam o acesso da população aos espaços de lazer e atividade física" (BRASIL - MINISTÉRIO DO ESPORTE, 2010, p. 26); a consolidação e ampliação do Prêmio Brasil de Esporte e Lazer de Inclusão Social; a meta de projetar o Brasil entre os dez mais vencedores esportivos nos próximos dez anos; promoção da chamada "gestão compartilhada dos equipamentos públicos de esporte e lazer" que tende a ser traduzida nas chamadas parcerias público-privadas; o fortalecimento da indústria esportiva, com a (suposta) criação de empregos por meio da realizações de grandes eventos esportivos.

Destaca-se que a ligação do produto final da III Conferência, o PDEL, com os megaeventos não quer dizer que nos debates e, mesmo, nas resoluções finais não constasse menção ao esporte e lazer como direitos sociais; mas discussões e resoluções existiram, contudo relegadas a segundo plano, se restringido a referendar o utilitarismo e as políticas de focalização do ME.

A chegada dos megaeventos na agenda nacional causou, também, um reordenamento estratégico do governo. A principal representação disso é o PPA 2012/201 - "Plano mais Brasil". Neste, o esporte está associado aos grandes eventos, sendo que dos quatro objetivos do documento, três estão relacionados à organização e participação do país na Copa FIFA 2014 e Jogos- Rio 2016: 1) Objetivo 0669 - ampliar e qualificar o acesso da população ao esporte e ao lazer, por meio de articulações intersetoriais, promovendo a cidadania, a inclusão social e a qualidade de vida; 2) Objetivo 0676 - elevar o Brasil à condição de potência esportiva mundialmente reconhecida, com apoio à preparação de atletas, equipes e profissionais, da base à excelência esportiva, com estímulo à pesquisa e inovação tecnológica, qualificação da gestão, melhoria e articulação das estruturas, com segurança e conforto nos espetáculos, fomentando

\footnotetext{
${ }^{1}$ Os dez eixos foram: 1 - Sistema Nacional de Esporte e Lazer; 2- Formação e Valorização Profissional; 3 Esporte, Lazer e Educação; 4 - Esporte, Saúde e qualidade de Vida; 5- Ciência e Tecnologia e inovação; 6Esporte de Alto Rendimento; 7- Futebol; 8 - Financiamento do Esporte; 9 - Infraestrutura Esportiva; 10 - Esporte e Economia; (BRASIL, 2010). Observa-se que o Sistema Nacional de Esporte e Lazer debatido na I Conferência Nacional e tema da segunda, reduz-se a um eixo nesta III edição do evento.
} 
a dimensão econômica; 3) Objetivo 0686 - coordenar, monitorar e fomentar os esforços governamentais de preparação e realização da Copa do Mundo FIFA 2014 e eventos a ela relacionados; e 4) Objetivo 0687 - Coordenar e integrar a atuação governamental na preparação, promoção e realização dos Jogos Olímpicos e Paraolímpicos Rio 2016, considerando a geração e ampliação do legado esportivo, social e urbano, bem como implantar a infraestrutura esportiva necessária.

Assim, no PPA 2012-2015 o Estado além de vincular o esporte "à remediação da vulnerabilidade social, em articulação com os Ministérios da Justiça e da Cultura, e não como um direito social a ser democratizado e universalizado" (FLAUSINO, 2013, p. 138), também, confirma a orientação do governo em privilegiar o esporte como emulador do crescimento econômico.

\section{Arranjo Institucional e Organizacional}

Os megaeventos provocaram um reordenamento no arranjo institucional do Ministério do Esporte (ME), na formação de instâncias colegiadas de poder e o surgimento de entidades da sociedade civil. Com efeito, em 2011 foi editado o Decreto $\mathrm{n}^{\circ} 7.629$ que estabeleceu a fusão das secretarias da área social do ME, dando origem a Secretaria Nacional de Esporte Lazer e Inclusão Social (SNELIS) e criou a Secretaria Nacional do Futebol e Direitos do Torcedor (SNFDT). Vejamos isso nas palavras do próprio governo:

A criação da Secretaria Nacional de Esporte, Educação, Lazer e Inclusão Social - SNELIS, se deu no processo de reestruturação do Ministério do Esporte, aprovada pelo Decreto $n^{\circ}$. 7.529, de 21 de julho de 2011, tendo em vista a necessidade de criar uma estrutura específica para organizar a Copa do Mundo de Futebol 2014 e assumir os programas e projetos relativos ao estatuto do torcedor, e ainda dotar de melhores condições o setor responsável pela Lei de Incentivo ao Esporte, cuja estrutura não comportava a crescente demanda (BRASIL, 2012, p.7).

Em 2012, é criada na estrutura na Secretaria Executiva do ME, a Assessoria Extraordinária de Coordenação dos Grandes Eventos Esportivos. As consequências destas mudanças estão nas palavras dos gestores da pasta.

Não há dúvidas que a mudança estrutural ocorrida no Ministério do Esporte em 2012 teve grande impacto nas áreas finalísticas, particularmente na SNELIS que foi a Secretaria mais afetada. Isso foi agravado pelo fato de ter ocorrido já na metade do ano, tendo a execução dos programas sido desenvolvida por estruturas diferentes no mesmo exercício. Outro fator importante foi à mudança na titularidade da pasta, ocorrida em outubro do mesmo ano, e em consequência, tendo causado nova mudança na gestão da SNELIS (BRASIL, 2012, p. 16).

Sobre a mudança na gestão do ME é preciso dizer que foi uma consequência dos escândalos envolvendo os convênios do Programa Segundo Tempo com Organizações Não Governamentais (ONGs), que supostamente beneficiaram o Partido Comunista do Brasil ${ }^{2}$. Mas o

\footnotetext{
2“Ex-vereadora está entre nove indiciados pela política federal”. 02 fev. 2013. Disponível em: $<$ http://www.gazetaregional.com.br/index.php/primeiro-caderno/gazeta-policial/3249-ex-vereadora-esta-entre- 
ME continuou como "feudo" deste partido, sendo dirigido de outubro de 2011 até dezembro de 2014, por Aldo Rebelo.

Em paralelo, o Governo Federal, seja por iniciativa própria, seja por determinação dos acordos firmados com a Federação Internacional do Futebol (FIFA) e com o Comitê Olímpico Internacional (COI), instituiu estruturas paralelas para a gestão dos megaeventos. Assim, em março de 2011 é sancionada a Lei federal no 12.396 (BRASIL, 2011a) que cria a Autoridade Pública Olímpica (APO), consórcio formado pelas três esferas de governo. Em âmbito estadual a APO foi ratificada em abril, através da Lei $n^{\circ} 5.949$ e, na esfera municipal, no mesmo período, pela Lei $\mathrm{n}^{\circ}$ 5.260. Essa nova instância possui como meta organizar a atuação dos três níveis de governo na organização dos Jogos Rio 2016.

Especificamente sobre a organização do evento de 2016 foi criado o Comitê Organizador dos Jogos Rio 2016 (COJO), instância sem fins lucrativos, dirigida pela primeira vez na história pelo presidente do Comitê Olímpico do país sede. Na sua estrutura, o COJO possui 16 personalidades do mundo esportivo nacional. Ele é financiado pelo COI, mas as três esferas de governo se comprometeram no Dossiê de candidatura, caso seja necessário, suprirem as carências do Comitê.

Para além dos marcos que citamos, o governo criou os comitês gestores para os Jogos Rio 2016 (CGOLÍMPIADAS) e para a Copa FIFA 2014 (CGCOPA). O alento é pequeno porque não envolve a participação popular, ficando restrito aos membros do bloco no poder.

A sociedade civil organizada, ligada ao campo da esquerda, também está mobilizada, observando atentamente a organização dos megaeventos. Como exemplos, podem ser citados os Comitês Populares da Copa FIFA 2014, estando presentes nas doze cidades sede, e o Comitê Popular dos Jogos Rio-2016, que acompanha e denuncia os abusos existentes na capital fluminense ${ }^{3}$.

\section{Legislação de exceção}

Como sede dos megaeventos esportivos, o país teve que adequar sua legislação aos interesses dos detentores dos monopólios Copa FIFA 2014 e Jogos Rio 2016. Assim, em 2009, foi instituído o Ato Olímpico, Lei no 12.035, que estabeleceu garantias à candidatura do Rio aos Jogos de 2016 e regras para sua realização.

O Ato olímpico possibilita aos membros do COI, do Comitê Organizador e turistas na época do evento privilégios e benesses que suplantam a legislação nacional. Como exemplo, a dispensa de visto para estrangeiros, a utilização pelo COI e Comitê Organizador de imóveis e/ou equipamentos pertencentes à União, proíbe qualquer tipo de uso dos símbolos olímpicos e ainda garante serviços de segurança, saúde, vigilância sanitária e serviços alfandegários e de imigração, bem como frequência de radiodifusão e de sinais aos membros do Comitê organizador (FLAUSINO, 2013).

Para a Copa FIFA 2014, outra legislação de exceção foi a Lei Geral da Copa, $n^{\circ}$ 12.663/2012 (BRASIL, 2012). Da mesma forma que o Ato Olímpico, ela assegurou os direitos de exploração e comercialização do megaevento, das vias de acesso e próximas dos locais, os direitos de imagens, sons e radiodifusão, a liberação de vistos aos membros vinculados a FIFA etc. Além disso, as empresas fornecedoras e prestadoras de serviços para o Mundial, escolhidas pela FIFA, estão isentas de pagamento de tributos (SOUSA, 2011).

Um exemplo de concessão aplicada pelo Estado brasileiro em sua legislação diz respeito ao Estatuto do Torcedor, a Lei 10.671 (BRASIL, 2003), que no seu artigo 13-A, inciso II, prevê as condições para a permanência do torcedor dentro dos estádios. Entre as condições

nove-indiciados-pela-policia-federal.html >. Acesso em: 03 mar. 2013.

${ }^{3}$ Informações disponíveis em: <www.portalpopulardacopa.org.br>. 
mínimas, estabelece: "não portar objetos, bebidas ou substâncias proibidas ou suscetíveis de gerar ou possibilitar a prática de atos de violência” (BRASIL, 2003, p?). Contudo, a Lei Geral da Copa suprimiu temporariamente o artigo supracitado, tendo em vista atender aos acordos da FIFA com a AB InBev.

Outra medida questionável adotada pelo governo foi a adoção do Regime Diferenciado de Contratações (RDC) no setor público, aprovado em 2011 pelo Congresso Nacional. O RDC flexibiliza a Lei $n^{\circ} 8.666 / 93$, nos processos de licitações e licenciamento das obras para os megaeventos esportivos, o que pode acarretar ainda mais fragilidade na execução e fiscalização do uso dos recursos públicos.

A esse conjunto de legislações ainda contam com leis estaduais próprias para os megaeventos, sejam leis de segurança, sejam leis de isenções, sejam leis de restrição territorial, enfim, rasgam a Constituição Federal de 1988 em favor das entidades esportivas e as megacorporações associadas. Portanto, o preço para sediar os megaeventos é alto, inclusive sendo necessário curvar a legislação nacional aos interesses dos proprietários destes negócios.

\section{Financiamento e gasto}

No que se refere ao financiamento, vamos discutir apenas as mudanças ocorridas no sentido de ampliar os recursos para o esporte olímpico, tendo em vista os Jogos Rio 2016. Desta forma, dinheiro para construção de estádios, para mobilidade urbana, para segurança entre outros, não será o foco do trabalho.

No âmbito do financiamento do esporte, em consonância com o PDEL e as necessidades de realização e participação do país nos megaeventos, a presidente Dilma sancionou a Lei $\mathrm{n}^{\circ}$ 12.395/2011 (BRASIL, 2011b) que alterou o programa Bolsa Atleta e criou os programas Bolsa Pódio e Cidade Esportiva. Além disso, este novo marco regulatório provoca mudanças tanto na constituição dos recursos para o esporte como a sua distribuição.

O item mais importante é aquele que define que os recursos destinados ao ME através de fontes orçamentárias, concursos prognósticos, do adicional de 4,5\% sobre cada bilhete, 1/3 deve ser repassado aos estados e ao Distrito Federal para serem utilizados prioritariamente em jogos escolares de modalidades olímpicas e paraolímpicas e, dos 2/3 restantes, 1/6 será destinado à Confederação Brasileira de Clubes (CBC) que deverá destinar $10 \%$ ao esporte escolar e 5\% ao esporte universitário, prêmio de concursos prognósticos da loteria esportiva federal não reclamados, doações, legados, patrocínios e outras fontes não especificadas, sendo a fisscalização dos recursos uma obrigação do Tribunal de Contas da União (TCU).

O primeiro destaque fica para o fato de o direcionamento do $1 / 3$ dos recursos repassados para as demais esferas de governo que serão investidos em jogos escolares, o que consideramos como um equívoco, pois, ao contrário de democratizar, cerceia ainda mais a vivência esportiva. Mas lembremo-nos de que isto está de acordo com os anseios do bloco de poder esportivo, ou seja, preparar uma nova geração olímpica (FLAUSINO, 2013).

O segundo aspecto é o direcionamento de recursos para clubes, caso dos CBC, para descobrir e formar talentos esportivos. Assim, a aliança com o capital é cada vez mais sem máscaras, sendo escancarada.

Ressalta-se que, para o recebimento dos recursos públicos, a legislação possui um avanço significativo quando condiciona esse recebimento à celebração de um contrato de desempenho firmado entre ME e entidades esportivas.

Ainda como resultado da realização dos megaeventos e o anseio em lançar o país entre os dez do quadro de medalhas, nos próximos dez anos, o governo lançou em 2012 o "Plano Brasil Medalhas 2016", que regulamenta alguns aspectos da Lei n ${ }^{\circ} 12.395 / 2011$. Os investimentos previstos com o Plano chegam a um bilhão de reais e priorizam as modalidades que o país possui mais chances de obter êxito em 2016, tanto olímpica como paraolímpica. 
Neste bojo, o governo ainda pretende ampliar o investimento no esporte olímpico por meio das empresas estatais. Conforme demonstram Teixeira, Matias e Mascarenhas (2013), no ciclo olímpico de 2009-2012 as empresas estatais investiram mais de R \$ 600 milhões. No ciclo olímpico 2013-2016, esse valor deve ser superado.

Destaca-se que o esporte olímpico possui outras fontes de financiamento, tais como: Lei Agnelo-Piva (BRASIL, 2001); Lei de Incentivo ao Esporte (BRASIL, 2006b); Bolsa Atleta (BRASIL, 2004b); Descentralização das unidades orçamentárias da União. Sendo assim, a chegada dos megaeventos esportivos, em especial, os Jogos Rio 2016, com a meta estabelecida no PDEL de o país estar entre os 10 do quadro de medalhas movimentam ainda recursos do fundo público no sentido de prover o esporte olímpico (FLAUSINO, 2013).

\section{Considerações Finais}

Nas últimas décadas os megaeventos, especialmente os internacionais, ganham destaques na agenda dos governos. Eles aceleram as modificações urbanas, catalisam recursos de diferentes fontes e vendem os países e as cidades para os principais mercados do globo.

O Brasil desde 2007 vem realizando eventos e megaeventos esportivos, o mais importante, os Jogos Olímpicos, ocorrerá em 2016, na cidade do Rio de Janeiro. Associado mais a questões mercantis de (re)estruturação de novos mercados, cidades e nichos econômicos do que a questões de democratização do esporte como um bem da humanidade, os megaeventos esportivos estão pautando a agenda pública no campo esportivo, bem como em outros setores do Estado.

Neste texto tratamos dos ajustes promovidos no país advindo dos megaeventos esportivos, com destaque para as questões de planejamento e formulação de políticas, para o novo arranjo institucional e governamental, para o ordenamento legal de exceção e para o financiamento.

As modificações estão subordinadas aos interesses de setores do mercado e das entidades esportivas, com o objetivo de garantir o sucesso dos eventos e megaeventos e dos negócios envolvidos. A população em geral fica na expectativa dos legados anunciados pelos organizadores: mas, na maioria das vezes, apenas legitima as ações, sendo excluída do processo decisório, dos benefícios diretos e, ainda, paga a conta da festa das empreiteiras, das corporações ligadas ao ramo da hotelaria e de turismo, da bonança dos cartolas e líderes políticos.

Como exemplo, temos a preparação para o principal megaevento esportivo ainda a ser realizado no país, os Jogos Olímpicos de 2016. Sem dúvida, é uma das prioridades da agenda governamental, sendo que o governo brasileiro ofertou aos dirigentes do Movimento Olímpico todas as garantias de proteção da propriedade intelectual para as marcas e símbolos olímpicos e paraolímpicos Rio 2016, bem como, aos parceiros internacionais e nacionais do evento. Além disso, garantiu a liberdade e/ou facilidades alfandegaria e de imigração para estrangeiros trabalhadores e clientes do produto Jogos Rio 2016 (BRASIL, 2009b).

Como ocorreu na Copa FIFA 2014, o governo também faz adaptações, exceções na legislação nacional, em âmbito local, estadual e federal, cumprindo todas as demandas da Carta Olímpica e o Contrato de Cidade-Sede. Além disso, para garantir o sucesso do evento, o Governo Federal estabeleceu novos arranjos institucionais, criou comitês e entidades para a organização do evento, bem como ampliou os recursos para o esporte olímpico.

De outra forma, acumulam denuncias dos movimentos sociais, em especial da Articulação Nacional dos Comitês Populares da Copa e das Olimpíadas ${ }^{4}$, de violações aos direitos humanos, de descaso com os recursos públicos, com os bens públicos e favorecimento explícito do setor privado.

\footnotetext{
${ }^{4}$ Informação disponível em: 〈http://www.portalpopulardacopa.org.br/>. Acesso em: 06 jan. 2014.
} 
Portanto, os megaeventos esportivos se articulam menos com a ampliação de direitos sociais e mais com o projeto de diversificação e expansão da acumulação capitalista para novos setores e mercados.

\title{
INFLUENCES OF MEGA SPORTS EVENTS ON THE AGENDA AND SPORTS POL- ICIES: PLANNING, INSTITUTIONAL ARRANGEMENT ,LEGAL ORDER, AND FINANCING
}

\begin{abstract}
This paper deals with the mega sports events, specifically on the influence exercise do in the agenda and sports policies. Therefore, a literature review of mega sports events and sport policy was carried out, as well as documentary research, based on the qualitative approach with exploratory nature. It was noticed that the mega sports events are associated more with market issues of (re)structuring new markets, cities and economic niches, and less with sports democratization issues. These issues caused changes in planning, institutional and legal arrangements and in sport funding in Brazil.

Keywords: State. Sports policies. Mega sports events.

\section{LAS INFLUENCIASDE LOS MEGA EVENTOS DEPORTIVOS EN LA AGENDA Y POLÍTICAS DESPORTIVAS: PLANIFICACÍON, ORGANIZACIÓN INSTITUCIO- NAL, SISTEMA LEGAL Y FINANCIAMENTO}

\section{Resumen}

Este trabajo se ocupa de los grandes eventos deportivos, específicamente sobre la influencia ejercida referente a las políticas deportivas. Para lograr ese objetivo, se hizo una revisión de la literatura de grandes eventos deportivos y de la política deportiva. También se llevó a cabo una investigación documental, de enfoque cualitativo y de naturaleza exploratoria. Se observó que los grandes eventos deportivos se asocian más con cuestiones de mercado(re)estructuración de nuevos mercados, ciudades y nichos económicos, que con cuestiones de democratización del deporte. Lo que causó cambios en la planificación, en los arreglos institucionales y legal es y en la financiación del deporte en Brasil.

Palabras clave: Estado. Políticas deportivas. Mega eventos deportivos.

\section{Referências}

BRASIL. Lei no $\mathbf{1 0 . 2 6 4}$ de 16 de julho de 2001. Disponível em:<www.planalto.gov.br/ccivil 03/leis/LEIS 2001/L10264.htm>. Acessoem: 13 nov .2012.

Lei $\mathbf{n}^{0} \mathbf{1 0 . 8 7 1}$ de 15 de maio de 2003. Disponível em: <http://www.planalto.gov.br/ccivil_03/Leis/L9615consol.htm>. Acesso em: 13 nov.2012.

Esporte, 2004a.

I Conferência Nacional do Esporte: documento final. Brasília: Ministério do

Lei $\mathbf{n}^{\circ} \mathbf{1 0 . 8 9 1}$ de 09 de julho de 2004. 2004b. Disponível em: <www.planalto.gov.br/ccivil 03/ ato2004-2006/2004/lei/110.891.htm $>$. Acesso em: 06 jan. 2014. 
2005 .

.Política Nacional do Esporte. Brasília: Governo Federal, Ministério do Esporte,

II Conferência Nacional do Esporte:documento final. Brasília: Ministério do Esporte, 2006a.

.Lei $\mathbf{n}^{\circ} \mathbf{1 1 . 4 3 8}$ de 29 de dezembro de 2006. 2006b. Disponível em:<www.planalto.gov.br/ccivil_03/_ato2004-2006/2006/lei/111438>.Acesso em:13 nov. 2012.

III Conferência Nacional do Esporte: cartilha de orientações. Brasília: Ministério do Esporte, 2009a.

Lei 12.035 , de 01 de outubro de 2009, institui o Ato Olímpico. Diário Oficial da Republica Federativa do Brasil, Brasília, DF, 01 de outubro de 2009b.

III Conferência Nacional do Esporte: documento final. Brasília: Ministério do Esporte, 2010.

Lei $\mathbf{n}^{\mathbf{0}} \mathbf{1 2 . 3 9 6}$ de 21 de março de 2011.2011a. Disponível em: <www.planalto.gov.br/ccivil 03/ato2011-2014/2011/Lei/L12396.htm>. Acesso em: 13 nov. 2012.

.Lei $\mathbf{n}^{\mathbf{0}} \mathbf{1 2 . 3 9 5}$ de 25 de março de 2011. 2011b.Disponível em: <www.planalto.gov.br/ccivil_03/leis/19615consol.htm>. Acesso em: 13 nov. 2012.

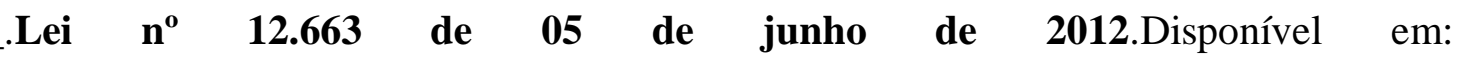
<www.planalto.gov.br/ccivil_03/_ato2011-2014/.../Lei/L12663.htm>. Acesso em: 13 nov. 2012.

CASTELAN, L. P. As conferências nacionais do esporte na configuração da política esportiva e de lazer no governo Lula (2003-2010). 2011.188f. Dissertação (Dissertação de Mestrado em Educação Física) - Faculdade de Educação Física, UNICAMP, Campinas-SP, 2011.

CASTELlANI FILHO, L. Educação Física, esporte e lazer: reflexões nada aleatórias. Campinas-SP: Autores Associados, 2013.

CASTELLANI FILHO, Lino. Megaeventos esportivos no Brasil: de expressão da política esportiva brasileira para a da concepção neodesenvolvimentista de planejamento urbano. Revista Motrivivência, Florianopolis, v. 26, n. 42, 2014.

CASTRO, D. G. Megaeventos esportivos e empreendedorismo urbano: os jogos olímpicos de 2016 e a produção do espaço urbano no Rio de Janeiro. Rio de janeiro, 2012. 124f. Dissertação (Mestrado em engenharia urbana) - Universidade Federal do Rio de Janeiro, Escola politécnica, Programa de Engenharia Urbana, Rio de Janeiro, 2012.

DAMO, A. S. O desejo, o direito e o dever: a trama que trouxe a Copa ao Brasil. Movimento, Porto Alegre, v. 18, n. 2, p. 41-81, abr./jun. 2012. 
FLAUSINO, M. Plano decenal: as políticas de públicas de esporte e lazer em jogo. Brasília, 2013. 155f. Dissertação (Mestrado) - Faculdade de Educação Física, UnB, Brasília, 2013.

MASCARENHAS, F. et al. O bloco olímpico:Estado, organização esportiva e mercado na configuração da agenda Rio 2016. Revista da Associação Latino-Americana de Estudos Sócio-Culturais do Esporte - ALESDE,Curitiba, v. 1, n. 2, p. 15-32, 2012.

MATIAS, W. B. O enigma olímpico: o controvertido percurso da agenda e políticas esportivas no governo Lula. 2013. 199f. Dissertação (Mestrado em Educação Física) - Faculdade de Educação Física, UnB, Brasília, 2013.

MELO, M. P. Esporte e dominação burguesa no século XXI: a agenda dos organismos internacionais e sua incidência nas políticas de esportes no Brasil de hoje. 2011. 344f. Tese (Doutorado em Serviço Social) - Centro de Filosofia e Ciências Humanas, UFRJ, Rio de Janeiro, 2011.

MIRANDA, Natália Nascimento; MASCARENHAS, Fernando. Os estudos olímpicos no Brasil: um mapeamento a partir dos periódicos científicos da Educação Física brasileira. Efdeportes, Buenos Aires, v. 16, n. 160, set. 2011.

RAEDER, S. Jogos e cidades: ordenamento territorial urbano em grandes eventos esportivos. Brasília: Ministério do Esporte, 2010.

SOUZA, C. E de. A política nacional de esporte no Brasil contemporâneo como estratégia para educar o consenso. 2011. 144f. Dissertação (Mestrado em Educação) -Faculdade de Educação, UFJF, Juiz de Fora-MG, 2011.

TEIXEIRA, M. R; MATIAS, W. B; MASCARENHAS, F. O financiamento do esporte olímpico no Brasil: uma análise do ciclo de Londres (2009-2012). Revista de Ciências Sociales, Iquique, n. 31, p.86-110, 2013.

Recebido em: 13/02/2015

Revisado em: 27/09/2015

Aprovado em: 10/08/2016

Endereço para correspondência:

wagner.matias@esporte.gov.br

Wagner Barbosa Matias

Universidade de Brasília

Campus Universitário Darcy Ribeiro

Brasília - DF, 70910-900 